\title{
Avaliação de Três Cultivares de Panicum maximum Jacq. sob Pastejo. Composição Química e Digestibilidade da Forragem ${ }^{1}$
}

\section{Patrícia Amarante Brâncio ${ }^{2}$, Domicio do Nascimento Junior ${ }^{3}$, Valéria Pacheco Batista Euclides ${ }^{4}$, Adair José Regazzi ${ }^{5}$, Roberto Giolo de Almeida ${ }^{6}$, Dilermando Miranda da Fonseca ${ }^{3}$, Rodrigo Amorim Barbosa ${ }^{6}$}

\begin{abstract}
RESUMO - O estudo foi conduzido com o objetivo de estimar o valor nutritivo da MS de três cultivares de Panicum maximum Jacq. submetidas ao pastejo rotativo, através dos teores de proteína bruta, fibra em detergente neutro, fibra em detergente ácido, lignina, celulose, sílica e digestibilidade in vitro da matéria orgânica em amostras de folhas e colmos. Estudou-se, também, no cultivar Tanzânia, a adubação nitrogenada no final do período chuvoso, adicional à de manutenção comum às demais cultivares. As amostragens foram realizadas em junho, setembro e novembro de 1998 e março de 1999. Algumas diferenças entre tratamentos foram observadas, apresentando, em geral, menor valor nutritivo no cv. Massai, com menores teores de proteína bruta e digestibilidade e maiores teores de fibra em detergente neutro, fibra em detergente ácido e lignina tanto nas folhas, como nos colmos. Sua utilização como opção forrageira deve basear-se em outras características agronômicas. O cv. Mombaça apresentou, em geral, maiores teores de sílica e seu valor nutritivo não foi afetado pela adubação nitrogenada no final do período chuvoso, exceto pelo aumento no teor de proteína bruta e pela redução do conteúdo de lignina e sílica em março. O valor nutritivo dos colmos foi inferior ao das folhas. O início do período chuvoso foi, em geral, a época de maior valor nutritivo da forragem em todos os tratamentos.
\end{abstract}

Palavras-chave: adubação nitrogenada, manejo de pastagens, pastejo rotativo, valor nutritivo

\section{Evaluation of Three Cultivars of Panicum Maximum Jacq. under Grazing. Chemical Composition and in Vitro Organic Matter Digestibility}

\begin{abstract}
A study was conducted to evaluate three cultivars of Panicum maximum Jacq. under rotational grazing for the nutritive value, where the estimates of crude protein, neutral detergent fiber, acid detergent fiber, lignin, cellulose, silica, and in vitro digestibility of the organic material were performed in samples of leaves and stems. Additional nitrogen was applied in cv. Tanzania at the end of the rainny season. Samples were taken in June, September, and October 1998 and in March 1999. Some differences among treatments were observed. In general, cv. Massai showed a lower nutritive value with lower crude protein and digestibility, and higher neutral detergent fiber, acid detergent fiber, and lignin, either in samples of leaves or in stems. Therefore, its utilization as a forage option should be based on other agronomic characteristics. The cv. Mombaça exhibited higher concentrations of silica and its nutritive value was not affected by nitrogen fertilization at the end of the rainny season, except for an increase in the percentage of crude protein and a reduction in the amount of lignin and silica in March. The nutritive value of the stems was inferior to the leaves. The nutritive value was highest in all treatments at the beginning of the rainny period.
\end{abstract}

Key Words: nitrogen fertilization, nutritive value, pasture management, pasture rotation

\section{Introdução}

Estudos referentes à avaliação de novos recursos forrageiros têm fundamental importância, já que há predominância na utilização de pastagens como a principal fonte de forragem para a criação bovina no Brasil. Da avaliação de 156 acessos de Panicum maximum Jacq. na EMBRAPA Gado de Corte, os 25 melhores foram submetidos a uma Rede de Ensaios Regionais, tendo como parâmetro o capim-colonião. Após avaliações agronômicas, os mais promissores foram o Tanzânia, o Mombaça e o Massai.

Estes materiais exibem um comportamento estacional quanto à produção de matéria seca, comum às gramíneas tropicais, em maior ou menor intensidade (Pedreira \& Mattos, 1981), devido ao

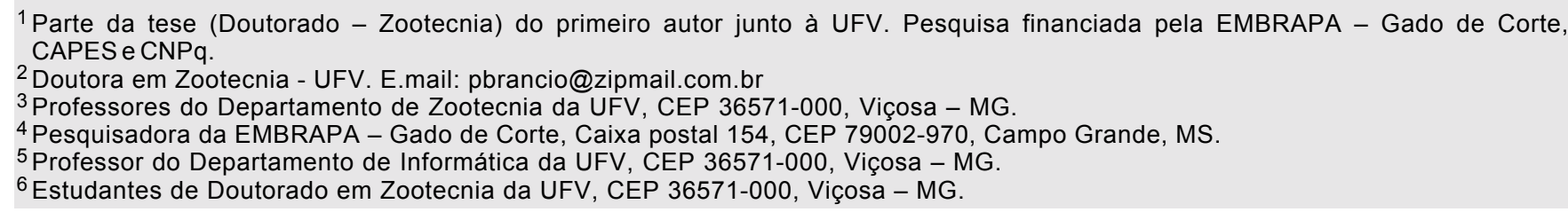


regime pluviométrico do Centro-Oeste brasileiro. Assim, tem-se estudado outra estratégia de manejo, além da introdução de espécies que possam melhorar a distribuição da produção de forragem ao longo do ano, que consiste em adubar com nitrogênio no final do período chuvoso, quando ainda há água disponível para as plantas utilizarem este elemento para o crescimento, proporcionando maiores disponibilidades de matéria seca até meados do período seco (Werner, 1986; Euclides, 1996).

A adubação com nitrogênio influencia também o valor nutritivo da forragem. Como os açúcares são utilizados na síntese de aminoácidos e proteínas, aumento no suprimento de nitrogênio para as plantas reduz o conteúdo de açúcares. As proteínas são acumuladas no conteúdo celular e têm o efeito de diluição dos componentes da parede celular, aumentando a digestibilidade. Por outro lado, ocorre maior lignificação, pois há maior crescimento e desenvolvimento das plantas. O resultado final no valor nutritivo dependerá, então, desses dois efeitos contrários, que interagem com os efeitos da temperatura, luz e água (Van Soest, 1994).

Além disso, o valor nutritivo da forragem pode ser bastante diferente para as diversas espécies forrageiras e partes da planta e, como relaciona-se com o consumo (Mertens, 1994), os estudos que caracterizam as pastagens em termos de composição química e digestibilidade da forragem são relevantes na avaliação de pastagens, pois auxiliam na indicação quanto à necessidade de suplementação, em determinadas épocas, para algumas categorias de animais. Ainda, o estudo do valor nutritivo da forragem contribui para a identificação dos possíveis pontos que restringem o consumo de nutrientes e, conseqüentemente, a produção animal.

$\mathrm{O}$ valor nutritivo do pasto pode ser obtido pelo corte de amostras de plantas, em número representativo da forragem total, observando-se que existem diferenças entre os valores nutritivos de partes de plantas e, principalmente, entre diferentes estádios de crescimento. Os métodos tradicionais utilizados para estimar o valor nutritivo da forragem incluem a determinação das concentrações de parede celular ou seus componentes, da proteína bruta e as estimativas da digestibilidade (Paterson et al., 1994).

Como objetivo de avaliar três cultivares de Panicum maximum Jacq. (cv. Tanzânia com dois níveis de adubação, cv. Mombaça e cv. Massai) sob pastejo rotativo, realizou-se uma pesquisa quanto ao valor nutritivo destas forrageiras antes e após o período de pastejo.

\section{Material e Métodos}

O estudo foi realizado em uma área de 6 ha pertencente à EMBRAPA Gado de Corte, em Campo Grande, Mato Grosso do Sul, nos meses de junho, setembro e novembro de 1998 e março de 1999, de forma a representar meados e fim da época seca, início e final da época chuvosa.

Os tratamentos foram: 1 - cv. Tanzânia $+50 \mathrm{~kg} / \mathrm{ha}$ de N; 2 - cv. Tanzânia + 100 kg/ha de N (sendo 50 kg/ha de $\mathrm{N}$ referentes à adubação de manutenção e $50 \mathrm{~kg} / \mathrm{ha}$ de $\mathrm{N}$ referentes a uma adubação adicional, realizada em fevereiro); 3 - cv. Mombaça $+50 \mathrm{~kg} / \mathrm{ha}$ de $\mathrm{N}$; e 4 - cv. Massai $+50 \mathrm{~kg} / \mathrm{ha}$ de N.

Após a implantação das pastagens, a partir de outubro a novembro de 1995, todos os tratamentos receberam adubação de manutenção em fósforo e potássio, com $200 \mathrm{~kg} /$ ha de 0-20-20, e em nitrogênio, com $250 \mathrm{~kg} /$ ha de sulfato de amônio (1996 e 1997) ou $110 \mathrm{~kg} /$ ha de uréia (1998). O tratamento Tanzânia + $100 \mathrm{~kg} /$ ha de $\mathrm{N}$ recebeu, além da adubação de manutenção comum a todos os tratamentos, uma adubação adicional de $50 \mathrm{~kg} /$ ha de nitrogênio no final do período chuvoso, sendo que, em 1995 e 1999, foram utilizados $250 \mathrm{~kg} / \mathrm{ha}$ de sulfato de amônio, enquanto em 1996, 1997 e $1998,110 \mathrm{~kg} / \mathrm{ha}$ de uréia.

Adotou-se o pastejo rotativo em quatro piquetes de 1,5 ha (um por tratamento), sendo cada piquete subdividido em seis áreas de 0,25 ha, com sete dias de utilização e 35 dias de descanso. Cada piquete foi pastejado por quatro bovinos (animais-teste), com peso médio inicial de aproximadamente $150 \mathrm{~kg}$, e animais adicionais, que, de acordo com a disponibilidade de forragem, foram colocados ou removidos, para que houvesse um resíduo após o pastejo de cerca de 2,0 a 2,5 t/ha de MS.

Em cada mês de amostragem, foram avaliadas três áreas de 0,25 ha em semanas consecutivas, para cada tratamento, antes da entrada e após a saída dos animais nos piquetes.

As amostras foram obtidas por meio do corte da forragem em quadrados-amostra de 1x1 m, ao nível do solo, alocados ao acaso. Estas amostras foram divididas em duas partes, utilizando-se apenas uma para formar amostras compostas (uma composta a cada cinco amostras), que foram separadas manualmente em folha (lâmina), colmo (colmo + bainhas), material morto e inflorescência, e secas em estufa a $65^{\circ} \mathrm{C}$, pesadas, moídas e acondicionadas em vidros para posteriores análises químicas. 
As amostras de folha e colmo foram analisadas utilizando-se o sistema de Espectrofotometria de Refletância no Infravermelho Proximal (NIRS), estimando-se os teores de proteína bruta (PB), digestibilidade in vitro da matéria orgânica (DIVMO), fibra em detergente neutro (FDN), fibra em detergente ácido (FDA), lignina, celulose, sílica, matéria orgânica (MO) e matéria seca (MS). Cerca de $20 \%$ do total de amostras teve os espectros colhidos e gravados no aparelho NIRS, que foram analisados pelos métodos convencionais, para efetuar a calibração necessária para relacionar os espectros das amostras que são obtidos por meio da radiação da amostra no infravermelho proximal (entre 1.100 e $2.500 \mathrm{~nm}$ ), ao passar pelo aparelho, e os valores obtidos pelas análises convencionais. As amostras foram analisadas quanto ao teor de $\mathrm{PB}$ (AOAC, 1990), quanto aos conteúdos de FDN, FDA, lignina por permanganato de potássio, celu- lose e sílica, utilizando-se a metodologia proposta por Goering \& Van Soest (1970), e quanto à DIVMO, pela modificação da técnica de Tilley \& Terry (1963) por Moore \& Mott (1974). Foram feitas calibrações separadamente para folha e colmo. Os valores obtidos no processo de calibração estão apresentados nas Tabelas 1 e 2 .

Foi utilizada a Análise Multivariada em Medidas Repetidas e, de acordo com a significância ou não da interação entre os efeitos do tratamento e época, foi adotado um procedimento estatístico apropriado. Quando a interação foi significativa, realizou-se teste de médias (teste de Tukey) entre tratamentos dentro de cada época e, quando a interação não foi significativa, realizou-se este mesmo teste de médias entre tratamentos, independentemente da época. O programa SAS (1990) foi utilizado para realização de todos os procedimentos de análise estatística.

Tabela 1 - Teores de fibra em detergente ácido (FDA), Celulose, Lignina e Sílica em folha antes do pastejo por bovinos em pastagens de cultivares de Panicum maximum Jacq.

Table 1 - Acid detergent fiber content (ADF), cellulose, lignin and silica in leaves before grazing in pastures of Panicum maximum Jacq. cultivars

\begin{tabular}{|c|c|c|c|c|c|}
\hline Cultivar & Jun./98 & Set./98 & Nov./98 & Mar./99 & Média \\
\hline & & & FDA $(\%)$ & & \\
\hline & & & $A D F(\%)$ & & \\
\hline Tanzânia + 50 kg/ha de N & 42,9 & 41,4 & 42,3 & 48,5 & $43,8^{\mathrm{ab}}$ \\
\hline Tanzânia +100 kg/ha de N & 41,8 & 41,5 & 41,3 & 45,7 & $42,6^{\mathrm{b}}$ \\
\hline Mombaça $+50 \mathrm{~kg} / \mathrm{ha}$ de N & 43,0 & 40,3 & 41,9 & 46,8 & $43,0^{\mathrm{ab}}$ \\
\hline \multirow[t]{3}{*}{ Massai $+50 \mathrm{~kg} / \mathrm{ha}$ de $\mathrm{N}$} & 44,8 & 41,1 & 43,0 & 47,8 & $44,2^{\mathrm{a}}$ \\
\hline & & & Celulose $(\%)$ & & \\
\hline & & & Cellulose (\%) & & \\
\hline Tanzânia + 50 kg/ha de N & 31,0 & 32,1 & 33,0 & 37,0 & $33,3^{\mathrm{a}}$ \\
\hline Tanzânia $+100 \mathrm{~kg} / \mathrm{ha}$ de N & 31,2 & 32,6 & 32,3 & 35,7 & $32,9^{\mathrm{a}}$ \\
\hline Mombaça $+50 \mathrm{~kg} / \mathrm{ha}$ de N & 29,0 & 28,9 & 29,7 & 34,1 & $30,4^{b}$ \\
\hline \multirow[t]{3}{*}{ Massai $+50 \mathrm{~kg} / \mathrm{ha}$ de $\mathrm{N}$} & 32,1 & 31,0 & 32,7 & 35,5 & $32,8^{\mathrm{a}}$ \\
\hline & & & Lignina $(\%)$ & & \\
\hline & & & Lignin (\%) & & \\
\hline Tanzânia + 50 kg/ha de N & 6,1 & 5,4 & 5,5 & 8,4 & $6,4^{b}$ \\
\hline Tanzânia $+100 \mathrm{~kg} / \mathrm{ha}$ de N & 6,0 & 5,3 & 5,4 & 7,7 & $6,1^{c}$ \\
\hline Mombaça $+50 \mathrm{~kg} / \mathrm{ha}$ de N & 6,7 & 6,1 & 5,9 & 8,5 & $6,8^{b}$ \\
\hline \multirow[t]{3}{*}{ Massai $+50 \mathrm{~kg} / \mathrm{ha}$ de $\mathrm{N}$} & 8,3 & 6,6 & 7,1 & 9,8 & $8,0^{\mathrm{a}}$ \\
\hline & & & Sílica(\%) & & \\
\hline & & & Silica $(\%)$ & & \\
\hline Tanzânia + 50 kg/ha de N & $5,7^{\mathrm{ab}}$ & $3,7^{\mathrm{b}}$ & $3,5^{\mathrm{b}}$ & $3,2^{\mathrm{b}}$ & 4,0 \\
\hline Tanzânia $+100 \mathrm{~kg} / \mathrm{ha}$ de N & $4,5^{\mathrm{b}}$ & $3,2^{\mathrm{b}}$ & $3,2^{b}$ & $2,1^{\mathrm{c}}$ & 3,3 \\
\hline Mombaça $+50 \mathrm{~kg} / \mathrm{ha}$ de N & $6,9^{\mathrm{a}}$ & $4,9^{\mathrm{a}}$ & $5,9^{\mathrm{a}}$ & $4,1^{\mathrm{a}}$ & 5,5 \\
\hline Massai $+50 \mathrm{~kg} / \mathrm{ha}$ de $\mathrm{N}$ & $4,0^{\mathrm{b}}$ & $3,0^{\mathrm{b}}$ & $2,8^{b}$ & $2,3^{c}$ & 3,0 \\
\hline
\end{tabular}

Médias seguidas pela mesma letra, na mesma coluna, para cada característica qualitativa, não diferiram entre si pelo teste Tukey a $5 \%$ de probabilidade.

Means followed by the same letter, in the same column, for each qualitative characteristic, are not different (P>.05) by Tukey test.

R. Bras. Zootec., v.31, n.4, p.1605-1613, 2002 
Tabela 2 - Teores de fibra em detergente ácido (FDA), celulose, lignina e sílica em colmos antes do pastejo por bovinos em pastagens de cultivares de Panicum maximum Jacq.

Table 2 - Acid detergent fiber content (ADF), cellulose, lignin and silica in the stems before grazing in pastures of Panicum maximum Jacq. cultivars

\begin{tabular}{|c|c|c|c|c|c|}
\hline Cultivar & Jun./98 & Set./98 & Nov./98 & Mar./99 & Média \\
\hline & & & FDA $(\%)$ & & \\
\hline & & & $A D F(\%)$ & & \\
\hline Tanzânia + 50 kg/ha de N & 50,7 & 46,1 & 47,1 & 55,0 & $49,7^{\mathrm{a}}$ \\
\hline Tanzânia $+100 \mathrm{~kg} / \mathrm{ha}$ de N & 49,7 & 46,0 & 46,7 & 53,0 & $48,9^{\mathrm{ab}}$ \\
\hline Mombaça $+50 \mathrm{~kg} / \mathrm{ha}$ de N & 51,0 & 44,4 & 45,4 & 52,0 & $48,2^{\mathrm{b}}$ \\
\hline \multirow[t]{3}{*}{ Massai $+50 \mathrm{~kg} / \mathrm{ha}$ de $\mathrm{N}$} & 51,8 & 45,5 & 45,0 & 51,9 & $48,6^{\mathrm{ab}}$ \\
\hline & & & Celulose $(\%)$ & & \\
\hline & & & Cellulose (\%) & & \\
\hline Tanzânia + 50 kg/ha de N & 35,0 & 36,4 & 37,1 & 41,2 & $37,4^{\mathrm{a}}$ \\
\hline Tanzânia $+100 \mathrm{~kg} / \mathrm{ha}$ de N & 34,8 & 37,5 & 36,4 & 39,5 & $37,0^{\mathrm{a}}$ \\
\hline Mombaça + $50 \mathrm{~kg} / \mathrm{ha}$ de N & 35,5 & 35,0 & 36,1 & 37,6 & $36,1^{\mathrm{a}}$ \\
\hline \multirow[t]{3}{*}{ Massai $+50 \mathrm{~kg} / \mathrm{ha}$ de $\mathrm{N}$} & 35,4 & 36,2 & 38,9 & 39,1 & $37,4^{\mathrm{a}}$ \\
\hline & & & Lignina $(\%)$ & & \\
\hline & & & Lignin $(\%)$ & & \\
\hline Tanzânia + 50 kg/ha de N & 11,7 & 5,9 & 5,6 & 8,8 & $8,0^{\mathrm{a}}$ \\
\hline Tanzânia $+100 \mathrm{~kg} / \mathrm{ha}$ de N & 12,6 & 4,6 & 6,2 & 10,4 & $8,4^{\mathrm{a}}$ \\
\hline Mombaça $+50 \mathrm{~kg} / \mathrm{ha}$ de N & 10,9 & 4,8 & 3,8 & 11,7 & $7,8^{\mathrm{a}}$ \\
\hline \multirow[t]{3}{*}{ Massai $+50 \mathrm{~kg} / \mathrm{ha}$ de $\mathrm{N}$} & 13,3 & 6,3 & 4,1 & 10,7 & $8,6^{\mathrm{a}}$ \\
\hline & & & Sílica (\%) & & \\
\hline & & & Silica $(\%)$ & & \\
\hline Tanzânia + 50 kg/ha de N & 4,2 & 2,5 & 1,9 & 2,4 & $2,8^{\mathrm{a}}$ \\
\hline Tanzânia $+100 \mathrm{~kg} / \mathrm{ha}$ de $\mathrm{N}$ & 3,7 & 2,1 & 2,0 & 2,1 & $2,5^{\mathrm{a}}$ \\
\hline Mombaça + 50 kg/ha de N & 5,4 & 2,6 & 2,2 & 2,3 & $3,1^{\mathrm{a}}$ \\
\hline Massai $+50 \mathrm{~kg} / \mathrm{ha}$ de $\mathrm{N}$ & 3,4 & 1,9 & 1,4 & 1,8 & $2,1^{\mathrm{a}}$ \\
\hline
\end{tabular}

Médias seguidas pela mesma letra na mesma coluna, para cada característica qualitativa, não diferiram entre si pelo teste Tukey $(P>0,05)$. Means followed by the same letter, in the same column, for each qualitative characteristic, for each sample type, are not different (P>.05) by Tukey test.

\section{Resultados e Discussão}

Verificou-se interação entre os fatores tratamento e mês de avaliação para a variável proteína bruta (PB) das folhas, tanto antes como após o período de pastejo. Antes do período de pastejo, os teores de proteína bruta das folhas no cultivar Massai foram sempre inferiores aos demais, embora esta diferença tenha sido significativa $(\mathrm{P}<0,05)$ apenas no primeiro mês de avaliação (Figura 1 a). No final do período seco e início do período chuvoso, não houve diferenças entre os tratamentos, enquanto, no final do período chuvoso, o tratamento cv. Tanzânia $+100 \mathrm{~kg} /$ ha de $\mathrm{N}$ foi superior aos demais $(\mathrm{P}<0,05)$, que não diferiram entre si $(\mathrm{P}>0,05)$. Comportamento semelhante foi observado após o período de pastejo, quando as folhas do cv. Massai apresentaram teores menores em relação aos outros cultivares, mas a diferença foi significativa $(\mathrm{P}<0,05)$ apenas em junho e março, com relação ao cv. Tanzânia $+100 \mathrm{~kg} / \mathrm{ha}$ de N, e em março, com relação ao cv. Mombaça (Figura 1 b). Os teores de PB das folhas reduziram após o período de pastejo, indicando que os animais consumiram as folhas com mais tecido protéico.

Diferenças e, ou, semelhanças entre cultivares sempre são esperadas, uma vez que o teor de PB conferido é inerente à planta, bem como conseqüência da maneira que cada cultivar se comporta sob determinado manejo (adubação, período de pastejo e período de descanso). Com a adubação adicional no final do período das chuvas no cultivar Tanzânia, foram observados aumentos significativos em termos de teores de PB apenas no final do período chuvoso (março de 1999), quando houve nítida superioridade $(\mathrm{P}<0,05)$ do tratamento cv. Tanzânia $+100 \mathrm{~kg} / \mathrm{ha}$ de $\mathrm{N}$, tanto em relação ao tratamento cv. Tanzânia + $50 \mathrm{~kg} / \mathrm{ha}$ de N, quanto aos outros tratamentos. Em se tratando de proteína bruta de folha, que consiste na parte da planta preferencialmente pastejada por bovinos, a adubação nitrogenada pode ser compensatória, uma vez que em março os demais tratamentos apresentaram teores próximos ou abaixo de 7\%, considerado crítico por Milford \& Minson (1965), abaixo do qual ocorreria restrição ao consumo vo- 
(a)

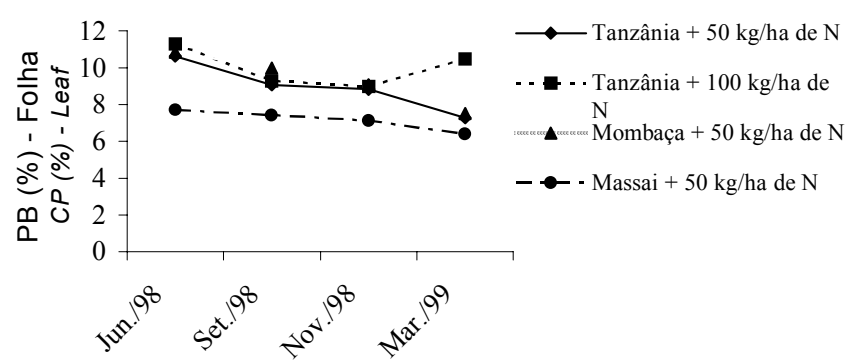

(b)

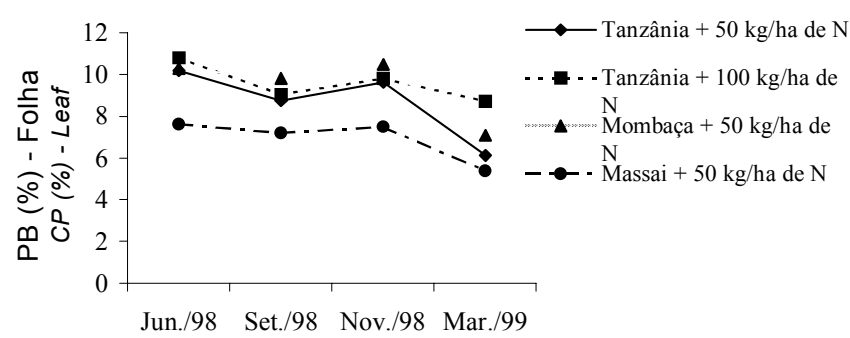

Figura 1 - Porcentagem de proteína bruta (PB) nas foIhas antes do pastejo (a) e após o pastejo por bovinos (b) em pastagens de cultivares de Panicum maximum Jacq.

Figure 1 - Percent of crude protein (PB) in leaves before (a) and after (b) grazing in pastures of Panicum maximum Jacq. cultivars.

luntário, por reduzir a atividade de microrganismos no rúmen e, assim, a taxa de digestão da celulose, aumentando o tempo de retenção da forragem no rúmen.

Os teores de PB dos colmos nas cultivares estudadas foram bastante inferiores aos encontrados nas folhas (Figura 2a), estando de acordo com relatos anteriores (Torregroza Sanches, 1993; Santos, 1997; Brâncio et al., 1997, Diogo, et al., 1995). Os valores foram sempre inferiores a $7 \%$, o que limitaria o consumo, e, ainda, não houve mudanças consistentes ao longo do período de utilização dos piquetes, indicando que os animais não consumiram os colmos, ou não consumiram partes dos colmos mais protéicos (Figura 2b). Entre os tratamentos, observou-se tendência a menores teores nos colmos do cv. Massai em relação aos demais, embora não tenha havido qualquer diferença significativa $(\mathrm{P}>0,05)$ em setembro e novembro, antes do período de pastejo. Após o período de pastejo, em média, os cultivares Tanzânia (com dois níveis de adubação) e Mombaça não diferiram entre si, e o cv. Massai (a)

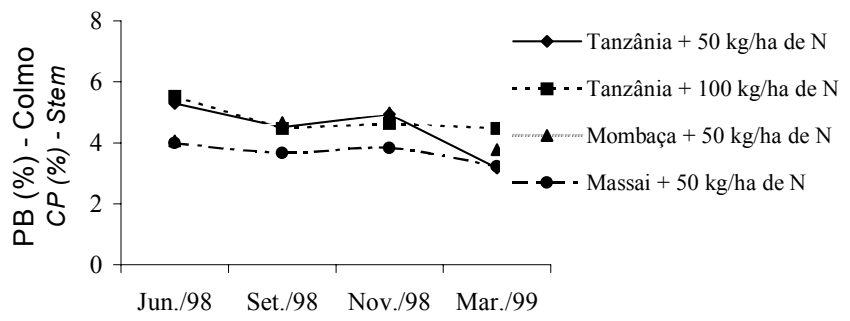

(b)

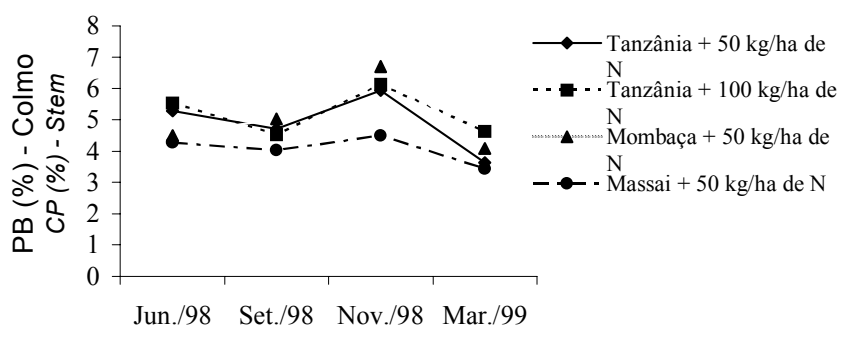

Figura 2 - Porcentagem de proteína bruta (PB) nos colmos antes do pastejo (a) e após o pastejo por bovinos (b) em pastagens de cultivares de Panicum maximum Jacq.

Figure 2 - Percent of crude protein (PB) in stems before (a) and after (b) grazing in pastures of Panicum maximum Jacq. cultivars.

apresentou o menor teor $(\mathrm{P}<0,05)$, embora não tenha diferido do cv. Mombaça.

A digestibilidade in vitro da matéria orgânica das folhas do cv. Massai, tanto antes como após o período de pastejo, foi inferior $(\mathrm{P}<0,05)$ à das demais cultivares, as quais não diferiram entre si $(\mathrm{P}>0,05)$ (Figura 3$)$. Segundo Lempp et al. (2000), que avaliaram os cultivares Tanzânia, Mombaça e Massai quanto à estrutura anatômica e observação do resíduo da incubação in vitro, o cultivar Massai apresenta menor fragilidade digestiva, sendo a maior freqüência da estrutura girder nesta cultivar uma das prováveis causas da restrição à maior digestão. Esta restrição à digestão pode ser atribuída à menor acessibilidade dos microrganismos ao conteúdo celular (Lempp et al., 1997).

A forragem residual após o pastejo apresentava menor digestibilidade em relação ao que havia antes do pastejo, o que indica que os animais selecionaram as partes das folhas mais digestíveis.

Quanto aos colmos, antes do período de pastejo, a cv. Massai também apresentou menores valores 
para digestibilidade, embora não tenha diferido do cv. Tanzânia $+50 \mathrm{~kg} /$ ha de N $(\mathrm{P}>0,05)$ (Figura 4a). Após o pastejo, não houve diferenças entre tratamentos ( $\mathrm{P}>0,05)$, e a digestibilidade foi pouca modificada ao longo do período de utilização do piquete (Figura 4b), sugerindo que o colmo provavelmente foi pouco consumido.

O conteúdo de fibra em detergente neutro, que, segundo Mertens (1994), está relacionado com o mecanismo de regulação do consumo, tanto antes como após o período de pastejo, foi superior em amostras de folhas no cv. Massai $(\mathrm{P}<0,05)$ em relação às demais, enquanto no $\mathrm{cv}$. Mombaça foi inferior às demais $(\mathrm{P}<0,05)$ (Figura 5). Conforme apresentado na Figura $6 \mathrm{a}$, antes do período de pastejo, os colmos do cv. Massia e cv. Tanzânia $+50 \mathrm{~kg} / \mathrm{ha}$ de N continham mais fibra em detergente neutro apenas em relação ao cv. Mombaça. Após o período de pastejo, a única diferença significativa $(\mathrm{P}<0,05)$ encontrada foi a superioridade do cv. Massai em relação ao cv. Mombaça (Figura 6b). O maior nível de nitrogênio no cv. Tanzânia não proporcionou mudanças nos teores de FDN, contrário a relatos de Belarmino

(a)

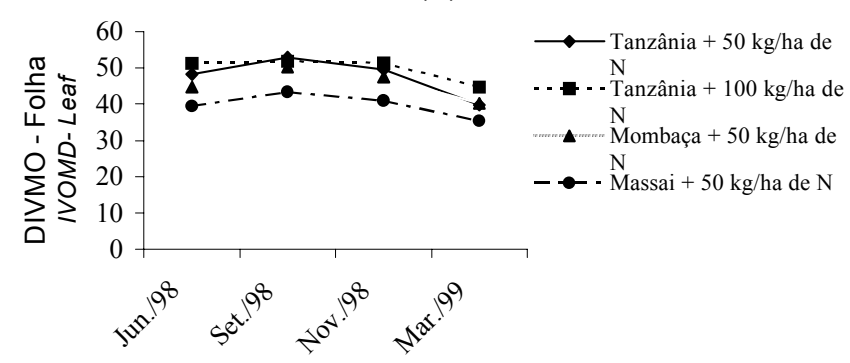

(b)

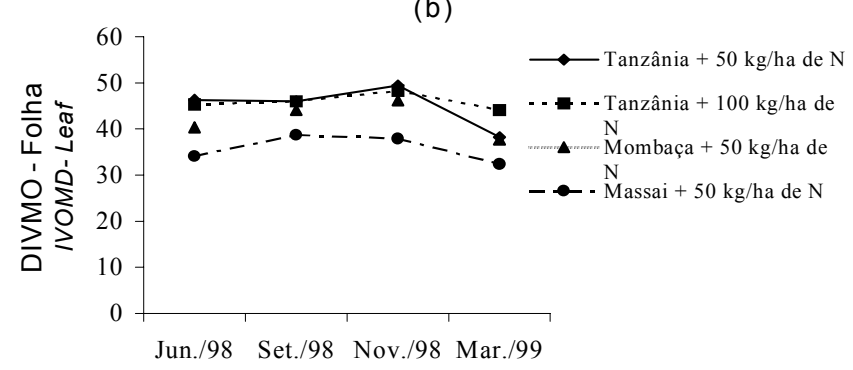

Figura 3 - Digestibilidade in vitro da matéria orgânica (DIVMO) das folhas antes do pastejo (a) e após o pastejo por bovinos (b) em pastagens de cultivares de Panicum maximum Jacq.

Figure 3 - In vitro organic matter digestibility (IVMOD) in leaves before (a) and after (b) grazing in pastures of Panicum maximum Jacq. cultivars. et al. (2001), que verificaram efeito linear negativo das doses de nitrogênio sobre os teores de FDN no cv. Tanzânia.

Em todas as cultivares e épocas, os valores de FDN nas folhas e colmos foram, em geral, superiores a $75 \%$, o que atuou, provavelmente, como o regulador do consumo de matéria seca nessas pastagens, mesmo considerando-se uma dieta composta exclusivamente por folhas.

O conteúdo de fibra em detergente ácido (FDA) nas folhas, antes do período de pastejo, foi diferente apenas entre a cv. Massai e o cv. Tanzânia $+100 \mathrm{~kg} / \mathrm{ha}$ de N (Tabela 1), enquanto os colmos do cv. Massai apresentaram conteúdo de FDA superior ao do cv. Mombaça (Tabela 2). Após o período de pastejo, não houve diferenças entre tratamentos quanto aos conteúdos de FDA nas folhas e, quanto aos colmos, em junho de 1999 houve superioridade $(\mathrm{P}<0,05)$ do cv. Massia (52,2\%) em relação ao cv. Tanzânia $+50 \mathrm{~kg} / \mathrm{ha}$ de N $(49,8 \%)$ e cv. Tanzânia $+100 \mathrm{~kg} / \mathrm{ha} \mathrm{de} \mathrm{N} \mathrm{(50 \% ),}$ mas não diferiu do cv. Mombaça $(51,8 \%)$. Nos demais meses, não houve diferenças entre tratamentos quanto aos conteúdos de FDA nos colmos, com

(a)

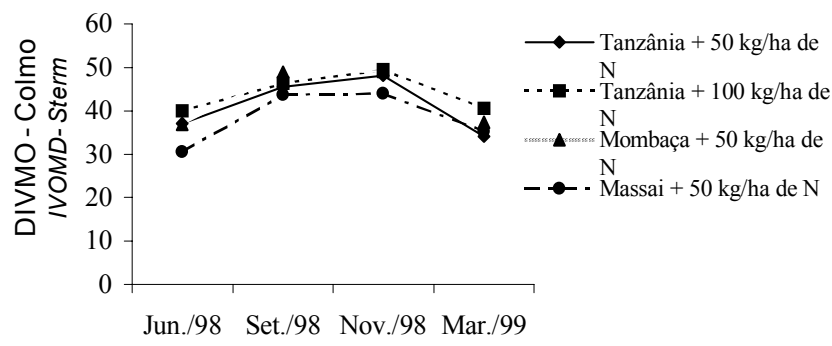

(b)

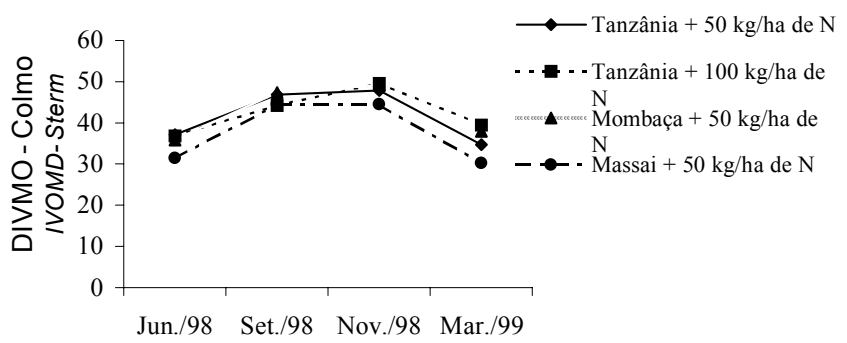

Figura 4 - Digestibilidade in vitro da matéria orgânica (DIVMO) dos colmos antes do pastejo (a) e após o pastejo por bovinos (b) em pastagens de cultivares de Panicum maximum Jacq.

Figure 4 - In vitro organic matter digestibility (IVMOD) in stems before (a) and after (b) grazing in pastures of Panicum maximum Jacq. cultivars.

R. Bras. Zootec., v.31, n.4, p.1605-1613, 2002 
(a)

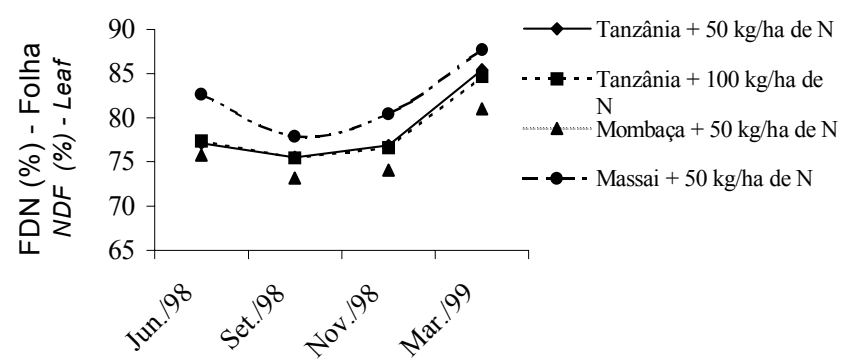

(b)

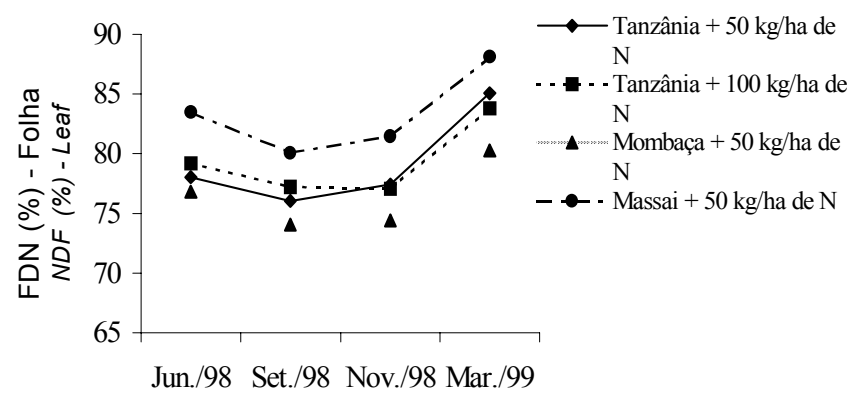

Figura 5 - Conteúdo de fibra em detergente neutro (FDN (\%)) em folhas antes do pastejo (a) e após o pastejo por bovinos (b) em pastagens de cultivares de Panicum maximum Jacq.

Figure 5 - Neutral detergent fiber content (NDF (\%)) in leaves before (a) and after (b) grazing in pastures of Panicum maximum Jacq. cultivars.

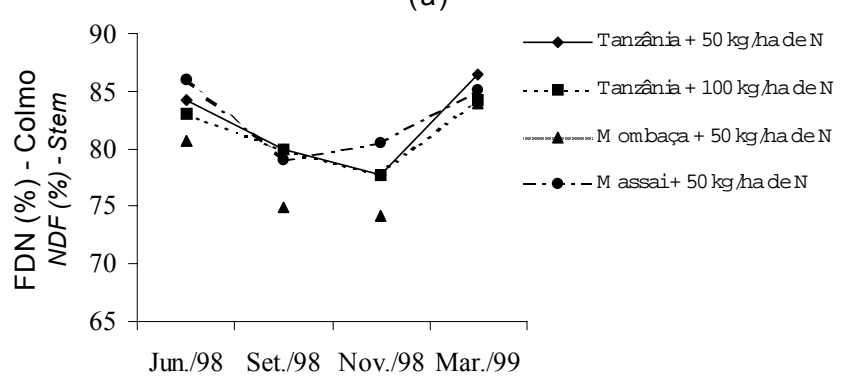

(b)

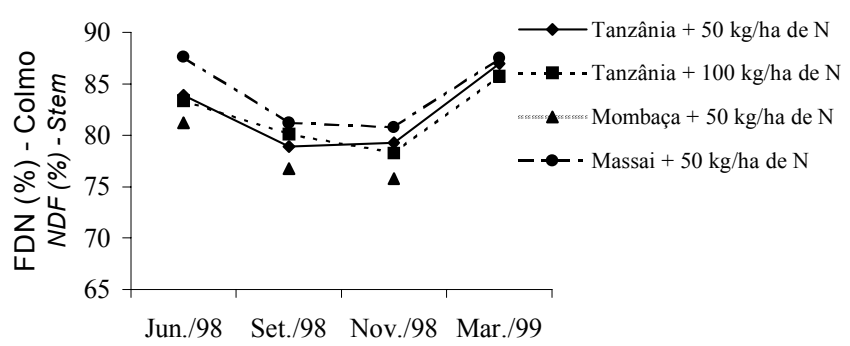

Figura 6 - Conteúdo de fibra em detergente neutro (FDN (\%)) em colmos antes do pastejo (a) e após o pastejo por bovinos (b) em pastagens de cultivares de Panicum maximum Jacq.

Figure 6 - Neutral detergent fiber content (NDF (\%)) in stems before (a) and after (b) grazing in pastures of Panicum maximum Jacq. cultivars.

$+100 \mathrm{~kg} / \mathrm{ha}$ de $\mathrm{N}$ foi o tratamento que apresentou menor valor $(\mathrm{P}<0,05)$ (Tabela 1). Provavelmente as folhas do cv. Massai apresentaram maior proporção de estruturas lignificadas (espessura da parede celular) e estruturas girder, que, segundo Wilson (1997), não apenas influencia a digestibilidade da matéria seca, mas afeta grandemente o padrão, a facilidade e a extensão da quebra da partícula do material durante a alimentação, ruminação e digestão. Neste experimento, a correlação entre teores de lignina e DIVMO de folhas foi de $-0,88$.

Os teores de lignina nos colmos não diferiram entre si nas cultivares estudadas $(\mathrm{P}>0,05)$, tanto antes (Tabela 2), como após o período de utilização dos piquetes pelos animais, com valores bem próximos aos apresentados antes do período de pastejo.

Em geral, as folhas e os colmos do cv. Mombaça apresentaram os maiores conteúdos de sílica, embora nem sempre esta diferença seja estatisticamente significativa $(\mathrm{P}>0,05)$ (Tabelas 1 e 2). Após o período 
de pastejo, o conteúdo de sílica permaneceu constante em todos os tratamentos. Alto teor de sílica na forragem está associado à menor palatabilidade e à redução do consumo, uma vez que a sílica não é absorvida e aproveitada pelos animais. Segundo Lempp et al. (1998), a sílica atua como uma barreira física para a colonização microbiana na lâmina foliar. Entretanto, os teores de sílica constituem uma característica da espécie forrageira que deve ser analisada com ressalvas. Como os teores nas folhas foram maiores que nos caules, mais próximos ao solo, conclui-se que a quantidade de sílica encontrada nas folhas pode ser atribuída à absorção pelo cultivar.

Avaliando o efeito do mês de amostragem nas variáveis que compõem o valor nutritivo, verificou-se que, em geral, setembro e novembro foram os de melhores resultados, pois houve tendência a maiores digestibilidades e menores conteúdos de fibra (em FDN e FDA) e de lignina. Entretanto, os teores de PB decresceram de junho de 1998 a março de 1999, com exceção do cv. Tanzânia $+100 \mathrm{~kg} / \mathrm{ha}$ de N. Assim, os carboidratos seriam utilizados, juntamente com o nitrogênio disponível, para a síntese de aminoácidos e proteínas, aumentando os teores de PB. Por outro lado, fatores favoráveis ao crescimento da planta também são para o desenvolvimento da parede celular e lignificação, principalmente na fase de alongamento do caule. Como resultado, em termos proporcionais, pode ocorrer redução dos teores de PB (Van Soest, 1994).

\section{Conclusões}

Entre os cultivares estudadas, o cv. Massai foi, em geral, o de menor valor nutritivo, e, portanto a sua utilização como opção forrageira deve basear-se em outras características agronômicas.

O valor nutritivo do cv. Tanzânia não foi afetado pela adubação nitrogenada no final do período chuvoso, exceto pelo aumento no teor de proteína bruta e pela redução do conteúdo de lignina e sílica em março.

O início do período chuvoso foi, em geral, a época de maior valor nutritivo da forragem.

\section{Literatura Citada}

ASSOCIATION OF OFFICIAL ANALYTICAL CHEMISTS AOAC. Official methods of analyses, v.15, n.1, p.72-74, 1990. BELARMINO, M.C.J.; PINTO, J.C.; ROCHA, G.P. et al. Teores de FDN e FDA na forragem de Panicum maximum Jacq. cv. Tanzânia em função da aplicação de doses de fósforo e nitrogênio. In: REUNIÃO ANUAL DA SOCIEDADE BRASILEIRA DE ZOOTECNIA, 38., 2001, Piracicaba. Anais... Piracicaba: Sociedade Brasileira de Zootecnia, 2001. p.242-243.

BRÂNCIO, P.A.; NASCIMENTO Jr., D.; MORAES, E.A. et al. Avaliação de pastagem nativa dos cerrados submetida à queima anual. 2. qualidade da dieta de bovinos. Revista Brasileira de Zootecnia, v.26, n.3, p.438-442, 1997.

DIOGO, J.M.S.; NASCIMENTO Jr., D.; TORREGROSA, S.L.J. Composição botânica da dieta selecionada por novilhos em pastagem natural de Viçosa-MG. Revista da Sociedade Brasileira de Zootecnia, v.24, n.6, p.884-895, 1995.

EUCLIDES, V.P.B. Técnicas de implantação, manejo e utilização de pastagens visando ao aumento de produtividade de bovídeos. Campo Grande: EMBRAPA Gado de Corte, 1996. $9 \mathrm{p}$.

GOERING, H.K.; Van SOEST, P.J. Forage fiber analyses, apparatus, reagents, procedures and some applications. Washington, D.C.: USDA (Agricultural Handbook, 379), 1970.

LEMPP, B.; EUCLIDES, V.P.B.; MORAIS, M.G. et al. Avaliações do resíduo da digestão de três cultivares de Panicum maximum. In: REUNIÃO ANUAL DA SOCIEDADE BRASILEIRA DE ZOOTECNIA, 37., 2000, Viçosa, MG. Anais... Viçosa, MG: Sociedade Brasileira de Zootecnia, 2000. p.43.

LEMPP, B.; EZEQUIEL, J.M.B.; SANTOS, J.M. et al. Observação da estrutura girder na taxa de digestão dos tecidos em lâminas de Panicum maximum Jacq. cv. Aruana e Vencedor. In: REUNIÃO ANUAL DA SOCIEDADE BRASILEIRA DE ZOOTECNIA, 34., Juiz de Fora. Anais... Juiz de Fora: Sociedade Brasileira de Zootecnia, 1997. p.15-17.

LEMPP, B.; EZEQUIEL, J.M.B.; SANTOS, J.M. et al. Influência das células epidérmicas na fragilidade de lâminas de Panicum maximum Jacq.. In: REUNIÃO ANUAL DA SOCIEDADE BRASILEIRA DE ZOOTECNIA, 35., 1998. Anais... Botucatu: Sociedade Brasileira de Zootecnia, 1998. v.2, p.209-211.

MERTENS, D.R. Regulation of forage intake. In: FAHEY Jr., G.C. et al. (Eds.). Forage quality evaluation and utilization. Nebraska: American Society of Agronomy, Crop Science of America, Soil Science of America, 1994. 988p.

MILFORD, R.; MINSON, D.J. Intake of tropical pasture species. In: CONGRESSO INTERNACIONAL DE PASTAGENS, 9., 1965, São Paulo, 1965. Anais... São Paulo: Universidade de São Paulo, 1965. v.1, p.815-822.

MOORE, J.E.; MOTT,G.O. Recovery of residual organic matter from in vitro digestion of forages. Journal of Dairy Science, v.57, n.10, p.1258-1259, 1974.

OLIVEIRA, T.N.; CARVALHO, M.S.B.; SILVA, A.L.C. et al. Composição química de gramíneas tropicais submetidas a duas frequências de corte. In: REUNIÃO ANUAL DA SOCIEDADE BRASILEIRA DE ZOOTECNIA, 38., 2001. Anais... Piracicaba: Sociedade Brasileira de Zootecnia, 2001. p. 107-108.

PATERSON, J.A.; BELYEA, R.L.; BOWMAN J.P. et al. The impact of forage quality and supplementation regimen on ruminant intake and performance. In: FAHEY, G.C.J. (Ed.). Forage quality, evaluation, and utilization. Lincoln, Madison: American Society of Agronomy, 1994. p.59-114.

PEDREIRA, J.V.S.; MATTOS, H.B. Crescimento estacional de vinte e cinco espécies ou variedades de capins. Boletim da Indústria Animal, v.38, n.2, p.117-143, 1981.

REGO, F.C.A.; CECATO, U.; CANTO, M.W. et al. Qualidade do capim Tanzânia (Panicum maximum Jacq. cv. Tanzânia-1)

R. Bras. Zootec., v.31, n.4, p.1605-1613, 2002 
manejado em diferentes alturas, sob pastejo. In: REUNIÃO ANUAL DA SOCIEDADE BRASILEIRA DE ZOOTECNIA, 38., 2001, Piracicaba. Anais... Piracicaba: Sociedade Brasileira de Zootecnia, 2001. p.117-118.

SANTOS, M.V.F. Métodos agronômicos para estimativa de consumo e de disponibilidade de forragem na Zona da Mata, Viçosa - MG. Viçosa, MG: Universidade Federal de Viçosa, 1997. 155p. Tese (Doutorado em Zootecnia) - Universidade Federal de Viçosa, 1997.

SAS INSTITUTE. SAS/STAT User's Guide, Versão 6, 4.ed., Cary: 1990. 846p.

TILLEY, J.M.A.; TERRY, R.A. A two stage technique for the in vitro digestion of forage crops. Journal of the British Grassland Society, v.18, n.2, p.104-111, 1963.

TORREGROZA SANCHEZ, L.J. Composição botânica e qualidade da dieta de novilhos esôfago-fistulados em pastagem natural de Viçosa. Viçosa, MG: Universidade Federal de Viçosa, 1993. Tese (Doutorado) - Universidade Federal de Viçosa, 1993.
Van SOEST, P.J. Nutritional ecology of the ruminant. 2.ed. Ithaca: Cornell University Press, 1994. 476p.

WERNER, J.C. Adubação de pastagens. Nova Odessa: Instituto de Zootecnia, 1986. 49p. (Boletim técnico, 18).

WILSON, J.R. Structural and anatomical traits of forages influencing their nutritive value for ruminants. In: SIMPÓSIO INTERNACIONAL SOBRE PRODUÇÃO ANIMAL EM PASTEJO, 1997, Viçosa, MG. Anais... Viçosa: Unviersidade Federal de Viçosa, 1997. p.411-429.

Recebido em: 16/10/01

Aceito em: 04/04/02 